\title{
Dispersion and re-agglomeration of graphite nanoplates in polypropylene melts under controlled flow conditions
}

\author{
C. Vilaverde, R.M. Santos, M.C. Paiva, J.A. Covas* \\ Institute for Polymers and Composites/I3N, University of Minho, Campus de Azurém, 4800-058 Guimarães, Portugal
}

\section{A R T I C L E I N F O}

\section{Article history:}

Received 25 February 2015

Received in revised form 3 July 2015

Accepted 10 August 2015

Available online 17 August 2015

\section{Keywords:}

A. Nanocomposites

B. Electrical properties

D. Optical microscopy

E. Extrusion

\begin{abstract}
A B S T R A C T
The kinetics of GnP dispersion in polypropylene melt was studied using a prototype small scale modular extensional mixer. Its modular nature enabled the sequential application of a mixing step, melt relaxation, and a second mixing step. The latter could reproduce the flow conditions on the first mixing step, or generate milder flow conditions. The effect of these sequences of flow constraints upon GnP dispersion along the mixer length was studied for composites with 2 and $10 \mathrm{wt} . \% \mathrm{GnP}$. The samples collected along the first mixing zone showed a gradual decrease of number and size of $\mathrm{GnP}$ agglomerates, at a rate that was independent of the flow conditions imposed to the melt, but dependent on composition. The relaxation zone induced GnP re-agglomeration, and the application of a second mixing step caused variable dispersion results that were largely dependent on the hydrodynamic stresses generated.
\end{abstract}

(c) 2015 Elsevier Ltd. All rights reserved.

\section{Introduction}

Graphene, a single layer of carbon atoms packed into a honeycomb crystal plane, is receiving intensive worldwide attention owing to its unique characteristics, namely mechanical, thermal, electrical and barrier properties [1,2]. It is a promising material for applications in sensors [3], electronic and photonic devices [4], clean energy [5], drug delivery and tissue engineering [6], biomaterials [7] and in polymer nanocomposites [8]. Graphene and its derivatives - graphene oxide [9-12], reduced graphene oxide [13$15]$, graphene quantum dots [16,17], graphene nanoribbons [18] and graphene nanomeshes [19] - have been produced by different routes, such as chemical vapor deposition (CVD) [20], growth on crystalline silicon carbide ( $\mathrm{SiC}$ ) [21] and mechanical exfoliation of graphite [22]. However, the current low throughput of these techniques severely limits the application to large-scale processes. Graphite nanoplates (GnP) [23], a thin form of graphite with thickness ranging from that of graphene to approximately $100 \mathrm{~nm}$, have recently attracted attention as an economically viable alternative for the development of functional and structural nanocomposites [24]. GnP-based polymer composites can be prepared by solution mixing and melt mixing. The former can achieve a suitable dispersion of GnP into polymeric matrices, but requires the use of hazardous organic solvents for the dissolution of most synthetic polymers [25]. On the other hand, melt blending is compatible with existing industrial procedures, providing the hydrodynamic

\footnotetext{
* Corresponding author.
}

stresses and residence times necessary to exfoliate and disperse GNP.

The incorporation of graphite nanoplates in PP could yield composites adequate for a range of technological applications [25-31]. Kalaitzidou et al. [26] showed that addition of GnP will simultaneously improve the barrier, thermal and mechanical properties. It was also demonstrated that even at loadings as low as 0.01 vol.\%, $\mathrm{GnP}$ is an effective nucleating agent of $\beta$-PP crystals, which exhibit higher impact strength and toughness in comparison with the $\alpha$ form [27]. GnP thickness and diameter influence the reinforcing effect, greater improvements in flexural strength and tensile properties having been obtained with smaller nanoplates [28,29]. Similarly, Milani et al. [31] reported that incorporation of GnP significantly increased the tensile properties and shifted upwards the degradation temperature of PP by more than $20^{\circ} \mathrm{C}$ (at a concentration of $12.3 \mathrm{wt}$.\%), but only those composites with higher filler content exhibited an increase of the electrical conductivity $\left(\approx 10^{-8} \mathrm{~S} \mathrm{~cm}^{-1}\right)$. Song et al. [25] also observed an increase of the initial degradation temperature of PP of approximately $26{ }^{\circ} \mathrm{C}$, but at much lower GnP content ( 0.42 vol.\%).

No systematic studies have apparently been published about the extent, mechanism and kinetics of the dispersion of GnP in polymer melts (in general, and particularly on PP) and on how they are influenced by the processing conditions and filler content. The work presented here investigates this topic, using a prototype modular small-scale extensional mixer that allows good control of the flow conditions of the polymer melt. Material samples can be obtained along the length of the mixer. Thus, the evolution of 
nanoparticle dispersion can be assessed and correlated with processing/reprocessing conditions and GnP concentration. The electrical conductivity of the composites was monitored. Compared to previous studies of the dispersion of carbon nanotubes (CNT) in the same polymer, the evolution of GnP dispersion in PP seems to be more gradual. Moreover, as observed before for CNT composites, as soon as hydrodynamic stresses are relieved significant reagglomeration takes place.

\section{Experimental}

\subsection{Materials}

Polypropylene copolymer Icorene CO14RM ${ }^{\circledR}$ (Ico Polymers, France), with a melt flow index of $13.0 \mathrm{~g} / 10 \mathrm{~min}\left(190^{\circ} \mathrm{C}, 2.16 \mathrm{~kg}\right)$ and a density of $0.9 \mathrm{~g} / \mathrm{cm}^{3}$ was used as matrix.

Graphite nanoplates $\mathrm{xGnP}^{\circledR}$ Grade C-750 (XG Sciences, Inc., Lansing., U.S.A.) - denoted here as GnP - have, according to the manufacturer, a size distribution ranging from very small $(100 \mathrm{~nm})$ to relatively large flakes $(1-2 \mu \mathrm{m})$, an average thickness of approximately $2 \mathrm{~nm}$ and a typical average surface area of $750 \mathrm{~m}^{2} / \mathrm{g}$. The morphology of as-received graphite nanoplates (in powder form) was observed by transmission electron microscopy (TEM), using a JEOL JEM1010 equipped with a CCD Orius camera and a tungsten filament as electron source, at an acceleration voltage of $100 \mathrm{kV}$. Particles were dispersed in a butyl alcohol solution $(1.2 \mathrm{~g} / \mathrm{l})$ under sonication (CREST 230T ultrasonic bath, $80 \mathrm{~W})$ at room temperature for $2 \mathrm{~h}$ and then directly deposited onto a cooper grid for subsequent observation. Optical microscopy (OM) was also carried out on a $\mathrm{BH} 2$ Olympus microscope coupled to a Leica DFC 280 camera. In this case, $10.0 \mathrm{mg}$ of GnP were gently dispersed in $4.25 \mathrm{ml}$ of epoxy resin, then spread onto a glass slide and dried at room temperature for $24 \mathrm{~h}$. A quantitative particle analysis (Fig. 1a)) performed on optical micrographs revealed GnP agglomerates with a projected average area of $6.7 \times 10^{5} \mu \mathrm{m}^{2}$. The figure also shows representative TEM and OM images.

\subsection{Composites preparation}

A prototype small-scale extensional mixer was attached to a Rosand RH8 capillary rheometer and used to manufacture the PP/ $\mathrm{GnP}$ composites. The mixer contains a sequence of converging/diverging channels that create a strong extensional flow component near to the axis, the design following the concept developed by Nguyen et al. [32] and used to disperse layered mineral silicates in different polymer matrices [33]. The efficiency of this approach for dispersing carbon nanofibers and carbon nanotubes (CNT) in PP melts has been demonstrated [34]. Using the same device, Jamali et al. [35] observed the re-agglomeration of CNT upon reprocessing (i.e., after re-feeding the rheometer with previously prepared nanocomposites). In the present work, the geometry of the mixer was modified in order to study nanoparticle re-agglomeration effects without the need to cool the composite, pelletize and remelt. As illustrated in Fig. 1(b), the device used here comprises a reservoir, where the polymer and $\mathrm{GnP}$ are fed in powder form and heated to a melt, a first mixing zone (equivalent to the conventional compounding stage, i.e., where the nanocomposite is prepared by melt mixing), a relaxation chamber (where the melt is subjected to quasi-quiescent conditions) and a second mixing zone (where reprocessing takes place, this being equivalent to processing of a previously compounded material). The first mixing zone consists of a vertical stack of ten $2 \mathrm{~mm}$ thick circular rings with alternating internal diameters ( 1 and $8 \mathrm{~mm}$ ), thus creating a series of five converging/diverging ( $8: 1$ and $1: 8)$ channels. The relaxation chamber is $24 \mathrm{~mm}$ long and has a diameter of $18 \mathrm{~mm}$. The second mixing zone creates a second series of five sequential converging/ diverging flows. Two different set-ups were assembled, designated as "set-up 1" inducing a $8: 1$ and $1: 8$ convergence/divergence (repeating the geometry of the first mixing zone), and a "set-up 2", inducing a 4:1 and 1:4 convergence/divergence sequence (using ten rings with internal diameters of $2 \mathrm{~mm}$ and $8 \mathrm{~mm}$ ). The assemblage of rings is mounted inside a sleeve that can be quickly removed from the body of the device, which is maintained at $200{ }^{\circ} \mathrm{C}$.

PP and 2 or 10 wt.\% of GnP were pre-mixed in powder form and fed into the reservoir of the rheometer. After pre-heating for $5 \mathrm{~min}$, the ram moved downwards at constant speed, forcing the melt through the mixer and out of the device in the form of a continuous filament. Three ram speeds were tested, corresponding to the average shear rates indicated in Table 1. Once the experiment was concluded, the sleeve containing the rings was removed and the individual parts were detached from each other. The nanocomposites contained in the $8 \mathrm{~mm}$ rings and in the relaxation chamber were collected and immersed in liquid $\mathrm{N}_{2}$, to freeze the GnP dispersion morphology. In this way, samples of composites along the axis of the mixer were made available. Table 1 includes an estimation of the maximum residence time of the melt in the mixer, obtained from the definition of $\bar{t}=V / Q$, where $V$ is the volume of the flow channel and $Q$ is the volumetric output.

\subsection{Composites characterization}

The dispersion of the GnP agglomerates in the PP matrix was assessed by transmission optical microscopy. Nanocomposite sec-
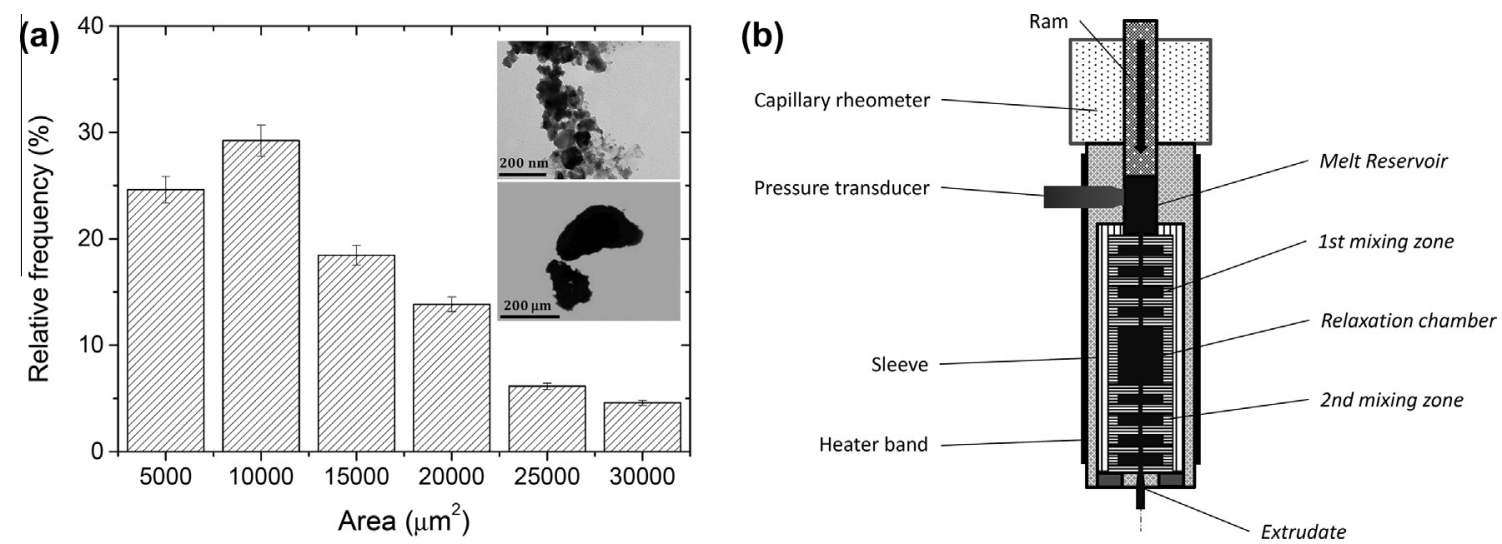

Fig. 1. Particle size distribution of as-received $\mathrm{GnP}(\mathrm{a})$ and schematic representation of the prototype mixer used for the composites preparation (b). 
Table 1

Processing conditions used to prepare the $\mathrm{PP} / \mathrm{GnP}$ nanocomposites $\left(\mathrm{T}=200^{\circ} \mathrm{C}\right)$.

\begin{tabular}{rlll}
\hline $\begin{array}{l}\text { Ram speed } \\
\left(\mathrm{mm} \mathrm{min}^{-1}\right)\end{array}$ & $\begin{array}{l}\text { Average } \\
\text { shear rate } \\
\left(\mathrm{s}^{-1}\right)\end{array}$ & $\begin{array}{l}\text { Total residence } \\
\text { time in the mixer } \\
(\mathrm{s})\end{array}$ & $\begin{array}{l}\text { Residence time in the } \\
\text { relaxation chamber }(\mathrm{s})\end{array}$ \\
\hline 15 & 450 & $223 \pm 2$ & $191 \pm 2$ \\
50 & 1494 & $63 \pm 2$ & $55 \pm 2$ \\
100 & 3006 & $32 \pm 3$ & $28 \pm 3$ \\
\hline
\end{tabular}

tions with $5 \mu \mathrm{m}$ thicknesses were cut along the flow direction using a Leitz 1401 microtome equipped with glass knifes with an angle of $45^{\circ}$ and operating at room temperature. Samples were also cut at perpendicular directions to the flow and analyzed. Since similar agglomerate dispersions were observed in the two directions, only longitudinal cuts were made in all samples. Micrographs were obtained with a Leica DFC 280 digital camera coupled to a $\mathrm{BH} 2$ Olympus microscope (with a $20 \times$ objective and $1.6 \times$ ocular magnification). The system provides a full frame of $1280 \times 1024$ (1.3 Mpixel), where each pixel corresponds to $0.52 \mu \mathrm{m}$. Quantitative particle analysis was performed using the Leica Application Suite 4.4 software. For each sample at least five images were analyzed, obtained from five microtomed sections.

The quantitative characterization of dispersion (or reagglomeration) of nano-fillers in a matrix is a difficult task, since the results are influenced by nanoparticle size, shape, orientation, presence of contaminants, etc. An overall index may be estimated, facilitating comparison and ranking of different samples. Nevertheless, it lacks detailed information that can only be obtained through the agglomerate area distribution, or the cumulative distribution of the agglomerate areas. Consequently, different authors have adopted or developed distinct dispersion assessment strategies (see, for example [34,36]). Here, the agglomerate area distribution was measured along the mixer length, as well as the number of agglomerates per unit area, $N$. The corresponding cumulative distribution of the agglomerate area ratio [33], represented by $F$, is obtained by plotting $F_{j}$ as a function of the agglomerate area, $A$, defined as $F_{j}=\frac{\sum_{i=1}^{j} A_{i}}{\sum_{i=1}^{n} A_{i}} \times 100$ where the numerator is the sum of the agglomerate areas from the smaller to the $j$ th agglomerate and the denominator is the total agglomerate area. In this work, we computed the size of the larger agglomerate contained in the subset of the smaller agglomerates that form either $50 \%$ or $90 \%$ of the total agglomerate area $\left(A_{\chi 50}\right.$, or $\left.A_{\chi 90}\right)$ obtained from the cumulative distribution $F$.

The dielectric properties of the nanocomposites were directly measured on the disks removed from the mixer with a Quadtech 1920 Precision LCR meter at a voltage of $1 \mathrm{~V}$ and a frequency ranging from $500 \mathrm{~Hz}$ to $1 \mathrm{MHz}$, at room temperature. The test fixture consisted of a parallel plate dielectric cell with $3 \mathrm{~mm}$ diameter electrodes that were gold coated by magnetron sputtering. Four test replications were carried out, average values being obtained. The real part of the electrical conductivity $\left(\sigma^{\prime}(\omega)\right)$ was calculated by:

$\sigma^{\prime}(\omega)=\omega \varepsilon_{0} \varepsilon^{\prime \prime}(\omega)$

where $\omega$ is the angular frequency, $\varepsilon_{0}$ is the permittivity in vacuum and $\varepsilon^{\prime \prime}(\omega)=\varepsilon^{\prime} \tan \delta$ is the loss permittivity, where $\tan \delta$ is the dissipation factor [37].

The surface morphology of cryo-fractured nanocomposites sputtered with a gold/palladium mixture was evaluated by Scanning Electron Microscopy (SEM) with a NanoSEM - FEI Nova 200, operating at an accelerating voltage of $5.00 \mathrm{kV}$ in backscattering electro image mode, coupled to an energy dispersive X-ray (EDAX- Pegasus X4 M) spectrometer.

\section{Results and discussion}

\subsection{Effect of processing conditions}

Fig. 2(a) and (b) presents micrographs illustrating the evolution of the $\mathrm{GnP}$ agglomerates morphology obtained from the capillary rheometer reservoir and along the extensional mixer for nanocomposites containing 2 and $10 \mathrm{wt} . \%$ of $\mathrm{GnP}$, prepared at different ram speeds using set-up 1 . Channels 3 and 5 belong to the first mixing zone, whereas channel 10 is the last of the second mixing zone. In all cases, a significant decrease of the size and number of the larger agglomerates from the reservoir to channel 5 is obvious. Along the relaxation chamber a drastic recovery of the magnitude of the $\mathrm{GnP}$ agglomerates is observed, thus suggesting that re-agglomeration took place. Further downstream, both size and number of agglomerates decrease. The effect of ram speed on dispersion is not clear. The composite containing a higher concentration of $\mathrm{GnP}$ exhibits a larger amount of GnP agglomerates.

From the analysis of all the micrographs it is possible to extract the $\mathrm{GnP}$ agglomerate size distribution for each location along the mixer. Fig. 3 presents this data for the nanocomposites containing 2 and $10 \mathrm{wt} . \%$ of $\mathrm{GnP}$ processed at $100 \mathrm{~mm} \mathrm{~min}^{-1}$. In the first case, the material remaining in the reservoir in the end of the experiment (which was subjected to heat and compression but not to flow) displays an asymmetrical size distribution of the GnP particles, with a larger number of agglomerates with areas smaller than $10 \mu \mathrm{m}^{2}$, and a progressively reduced number as the area increases up to $105 \mu^{2}$. After flowing through the first part of the mixer, the shape of the distribution is maintained, with a gradual but noticeable decrease of the number of agglomerates due to repetitive exposure to the hydrodynamic normal and shear stresses. At the relaxation chamber, where these stresses become negligible, the size distribution shifts upwards, approaching values not far from those at the reservoir. Dispersion regains pace in the second mixing zone, the size distribution attained at the outlet (channel 10) being similar to that reached at the end of the first mixing zone (channel 5). Thus, it appears that the morphology induced by melt mixing is unstable, and when the hydrodynamic stresses are sufficiently low the interfacial forces become dominant, similarly to the behavior of colloids and polymer blends and quantified by the capillary number $[38,39]$. Indeed, in the case of suspensions containing agglomerates of solid particles, Scurati et al. [40] defined a fragmentation number given by the ratio between hydrodynamic stresses and cohesive strength of the agglomerate, rupture occurring for material-dependent threshold values. The evolution of agglomerate size distribution for the composite with higher graphite concentration is similar, except for the behavior in the relaxation chamber, where broadening of the distribution to larger particle sizes is observed, i.e., large agglomerates are formed.

Table 2 presents the total number and maximum size of GnP agglomerates contained in $50 \%$ and $90 \%$ of the total agglomerate area measured at the same locations, ram speeds and compositions depicted in Fig. 3. The evolution of these dispersion indicators is also in general agreement with Fig. 3: (i) the material at the reservoir has a higher number of larger agglomerates, (ii) agglomerate size and number decrease up to channel 5 , (iii) in the relaxation chamber, a tendency to return to the agglomerate size and number similar to the reservoir (before inducing mixing) is observed, (iv) at channel 10 the values of the dispersion indicators are close to those at channel 5. As expected, nanocomposites with $10 \mathrm{wt} . \% \mathrm{GnP}$ contain a greater number of larger agglomerates throughout the entire sequence compared to those with $2 \%$, but maintain the overall tendency displayed by the latter. Table 2 also shows that ram speed (i.e., deformation rate) has little effect on dispersion, as only slightly more and larger GnP agglomerates are present on the 
(a)

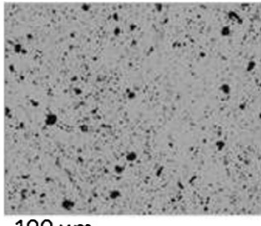

$100 \mu \mathrm{m}$

Reservoir
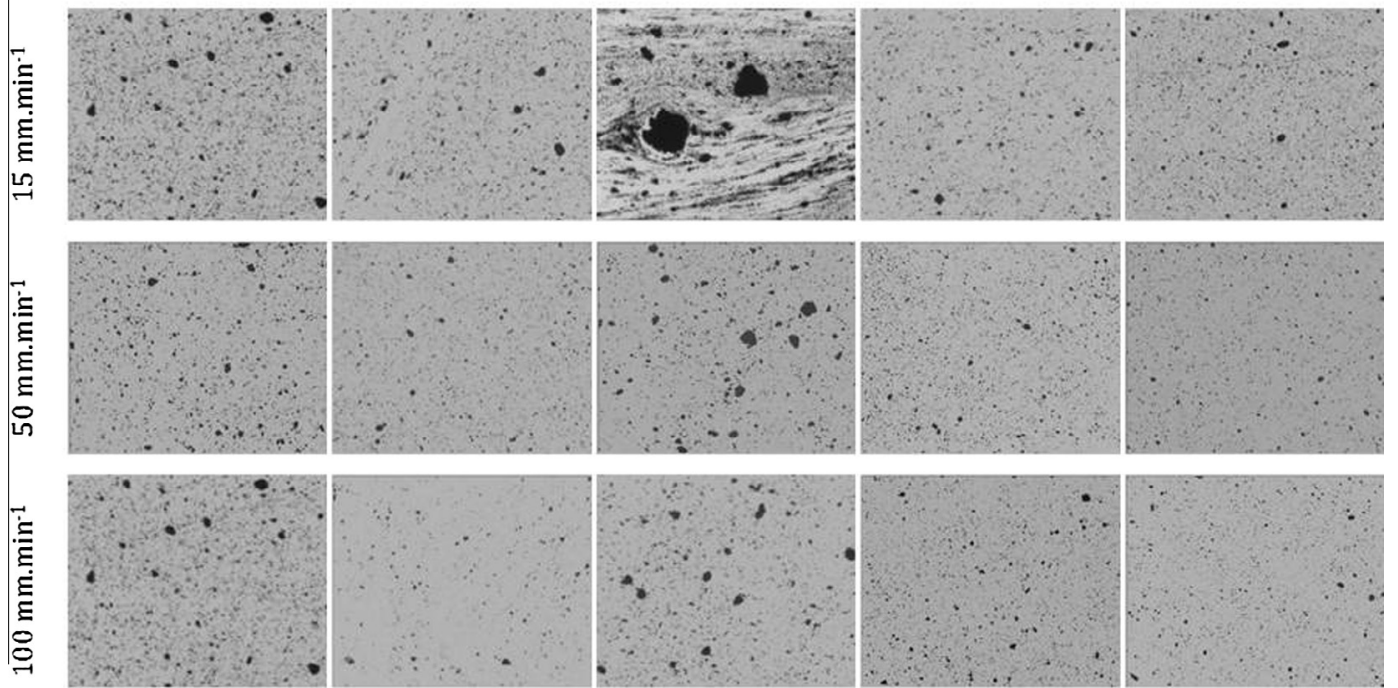

Channel 3

Channel 5

Relaxation

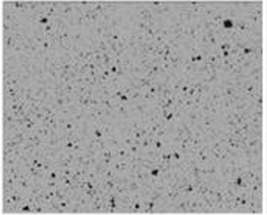

Channel 8

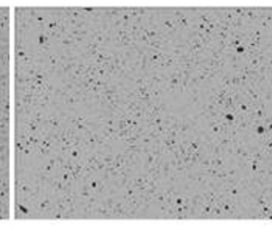

Channel 10

(b)

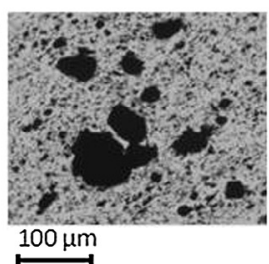
chamber

\section{Reservoir}
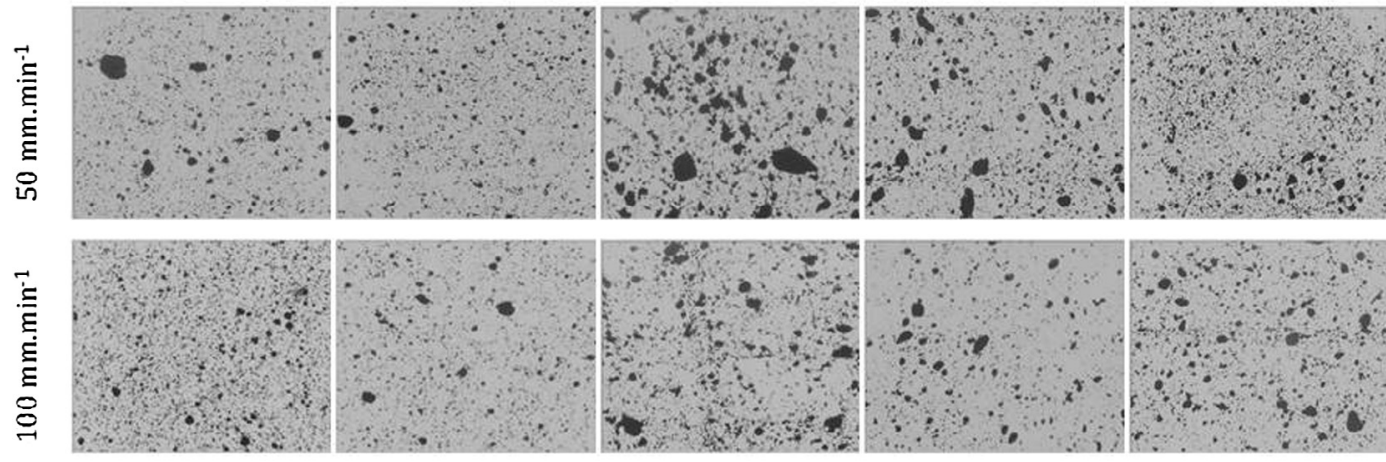

Channel 3
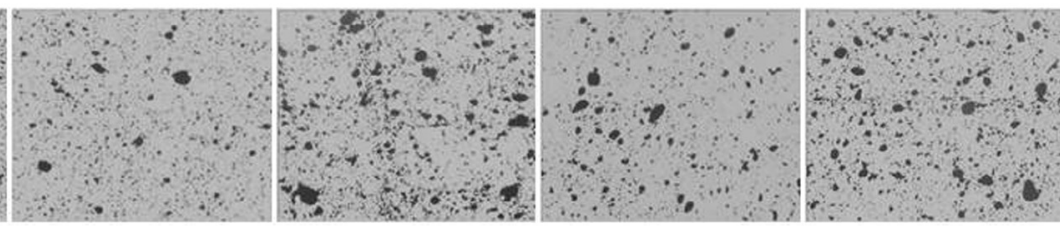

chamber

Channel 8

Channel 10

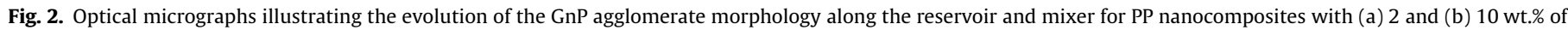
$\mathrm{GnP}$, prepared at different ram speeds using set-up 1 .

nanocomposites prepared at the lower rate. Nanocomposites generally exhibit significant non-Newtonian response [41], hence differences in viscosity of suspensions with dissimilar filler content at the high shear rate range, and thus in hydrodynamic stresses, could be relatively small. This is confirmed by the melt pressure readings at the entrance of the mixer (see Fig. 1) presented in Table 3. The total pressure drop (proportional to shear stress and therefore to viscosity) is observed to increase with the addition of GnP and with its concentration. However, the pressure increase observed upon increasing the

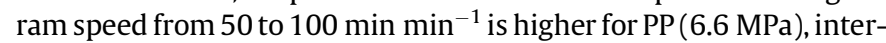
mediate for the nanocomposite with $2 \% \mathrm{GnP}(6 \mathrm{MPa})$ and lower for the nanocomposite containing $10 \% \mathrm{GnP}(5.4 \mathrm{MPa})$. 

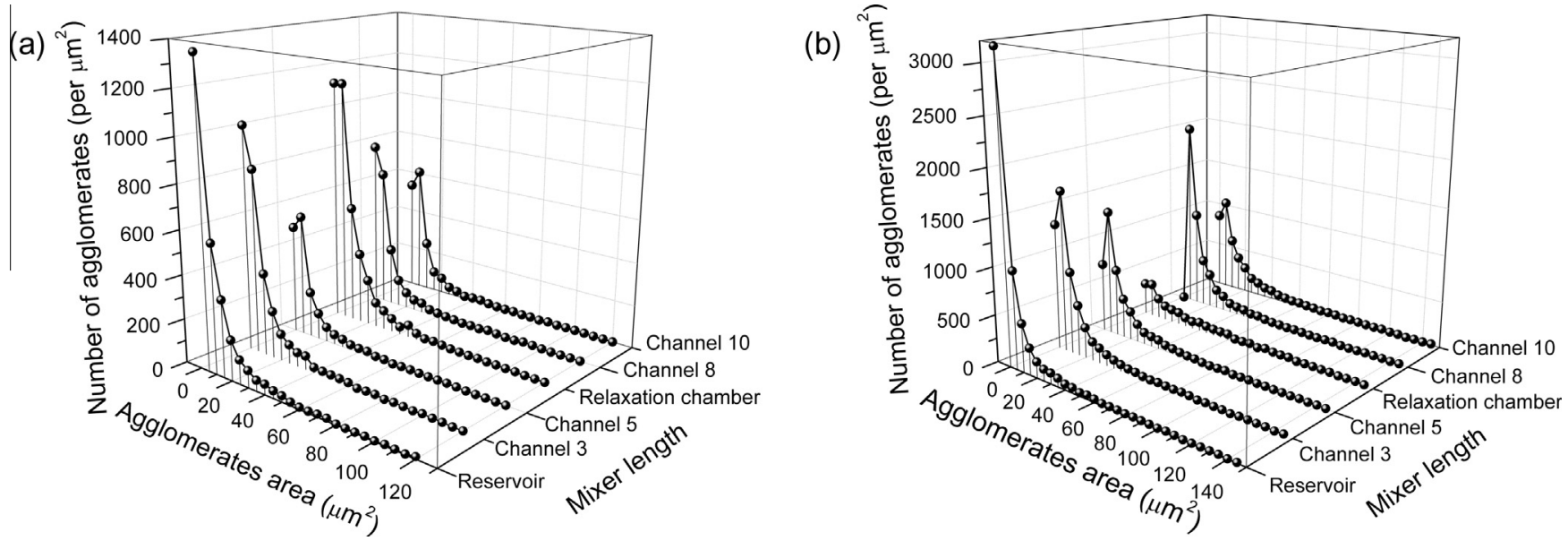

Fig. 3. Size distribution of GnP agglomerates of PP nanocomposites containing (a) 2 and (b) 10 wt.\% of GnP prepared at 100 mm min ${ }^{-1}$ using set-up 1.

Table 2

Dispersion characterization of PP nanocomposites with 2 and 10 wt.\% of GnP prepared at 50 and $100 \mathrm{~mm} \mathrm{~min}^{-1}$.

\begin{tabular}{|c|c|c|c|}
\hline Set up 1 & $A_{\chi 50}\left(\mu \mathrm{m}^{2}\right)^{\mathrm{a}}$ & $A_{\chi 90}\left(\mu \mathrm{m}^{2}\right)^{\mathrm{b}}$ & $\mathrm{N}$ per unit area $\left(\mathrm{mm}^{-2}\right)$ \\
\hline \multicolumn{4}{|c|}{$\begin{array}{l}\text { PP nanocomposites with } 2 \text { wt.\% of GnP } \\
50 \mathrm{~mm} \mathrm{~min}^{-1}\end{array}$} \\
\hline Reservoir & 26 & 241 & 4106 \\
\hline Channel 3 & 23 & 152 & 2199 \\
\hline Channel 5 & 16 & 75 & 1057 \\
\hline Relaxation & 26 & 167 & 3819 \\
\hline Channel 8 & 24 & 140 & 1617 \\
\hline Channel 10 & 18 & 88 & 1766 \\
\hline \multicolumn{4}{|c|}{$100 \mathrm{~mm} \mathrm{~min}^{-1}$} \\
\hline Channel 3 & 25 & 108 & 2811 \\
\hline Channel 5 & 24 & 94 & 1444 \\
\hline Relaxation & 24 & 140 & 3678 \\
\hline Channel 8 & 19 & 86 & 2007 \\
\hline Channel 10 & 16 & 68 & 1628 \\
\hline \multicolumn{4}{|c|}{$\begin{array}{l}\text { PP nanocomposites with } 10 \text { wt.\% of GnP } \\
50 \mathrm{~mm} \mathrm{~min}^{-1}\end{array}$} \\
\hline Reservoir & 236 & 6328 & 6418 \\
\hline Channel 3 & 30 & 516 & 6774 \\
\hline Channel 5 & 26 & 220 & 5456 \\
\hline Relaxation & 244 & 1586 & 2108 \\
\hline Channel 8 & 60 & 652 & 4586 \\
\hline Channel 10 & 45 & 298 & 4439 \\
\hline \multicolumn{4}{|c|}{$100 \mathrm{~mm} \mathrm{~min}^{-1}$} \\
\hline Channel 3 & 44 & 343 & 5582 \\
\hline Channel 5 & 30 & 232 & 4276 \\
\hline Relaxation & 91 & 687 & 2957 \\
\hline Channel 8 & 58 & 460 & 4729 \\
\hline Channel 10 & 57 & 308 & 5039 \\
\hline
\end{tabular}

Size of the larger agglomerate in the set of smaller agglomerates that form $50 \%$ of the total agglomerate area (a) or $90 \%$ of the total agglomerate area (b).

Table 3

Total pressure drop in the mixer, for PP nanocomposites containing 2 or $10 \mathrm{wt} . \% \mathrm{GnP}$, at two ram speeds, for set-up 1 and 2 .

\begin{tabular}{lclc}
\hline Material & $\begin{array}{l}\text { Ram speed } \\
\left(\mathrm{mm} \mathrm{min}^{-1}\right)\end{array}$ & $\begin{array}{l}\text { Pressure drop } \\
\text { set up 1 (MPa) }\end{array}$ & $\begin{array}{l}\text { Pressure drop } \\
\text { set up 2 (MPa) }\end{array}$ \\
\hline PP & 50 & 17.1 & 9.80 \\
& 100 & 23.7 & 13.2 \\
PP/2 wt.\% GnP & 50 & 18.3 & \\
& 100 & 24.3 & 14.9 \\
PP/10 wt.\% GnP & 50 & 24.3 & \\
& 100 & 29.7 & \\
\hline
\end{tabular}

Fig. 4 shows the evolution of GnP agglomerate dispersion along the mixer at three ram speeds and two graphite concentrations. The selected dispersion indicator was area ratio, which provides information about the overall dispersion achieved. Within the experimental error, the evolution of $A_{r}$ for each type of nanocomposite is independent of ram speed, except at the relaxation chamber. Along the first mixing section the threshold stress for rupture or erosion of the agglomerates is attained even at the lowest deformation rate, the non-Newtonian character of the flow reducing the effect of variations in shear and extensional rate. As soon the material enters the relaxation chamber the shear stress becomes too low and significant re-agglomeration occurs, with $A_{\mathrm{r}}$ returning to a value close to that measured in the reservoir. Re-agglomeration develops along the relaxation chamber. The lower the ram speed (i.e., the higher the residence time), the higher the $A_{r}$ attained toward the end of this chamber.

The evolution of GnP agglomerate dispersion along the first mixing section seems to be essentially linear, with a rate depending on GnP concentration. This rate should be associated to the intensity of the hydrodynamic stresses, which in turn result from the existing viscosity levels. However, even though higher GnP concentration induces faster dispersion, the final morphology is still coarser. The observed gradual dispersion is quite different from that of $\mathrm{PP} / \mathrm{CNT}$ composites prepared in the same device, where a stepwise evolution was seen $[34,35]$. This evolution was interpreted as evidence of the abrupt rupture of CNT agglomerates into smaller size when exposed to a certain stress level during a given time. In between-steps, continuous erosion of the agglomerates could take place. For example, for silica agglomerates, it was shown that the critical stress for erosion is lower than that for rupture and once erosion starts it continues for long times [40]. Concurrent rupture and erosion mechanisms in CNT dispersion was proposed by Kasaliwal et al. [36], based on the theoretical background previously developed by Manas-Zloczower et al. [40,42]. In the case of GnP agglomerates, it is difficult to distinguish whether erosion, rupture into progressively smaller agglomerates, or a combination of both prevails. Eventually, it will depend on the initial size of the agglomerates, which varies with filler concentration (see Fig. 2 and Table 2).

After re-agglomeration in the relaxation chamber, an initial significant reduction in $A_{r}$ is observed for the composite with lower $\mathrm{GnP}$ concentration. The dispersion in the second mixing zone regains its linear progress, albeit at a smaller pace. In a few experiments, the final value of $A_{r}$ after passing the second mixing zone seemed higher than that already achieved at channel 5 (i.e., end of first mixing zone). Fig. 5 shows representative SEM micrographs 

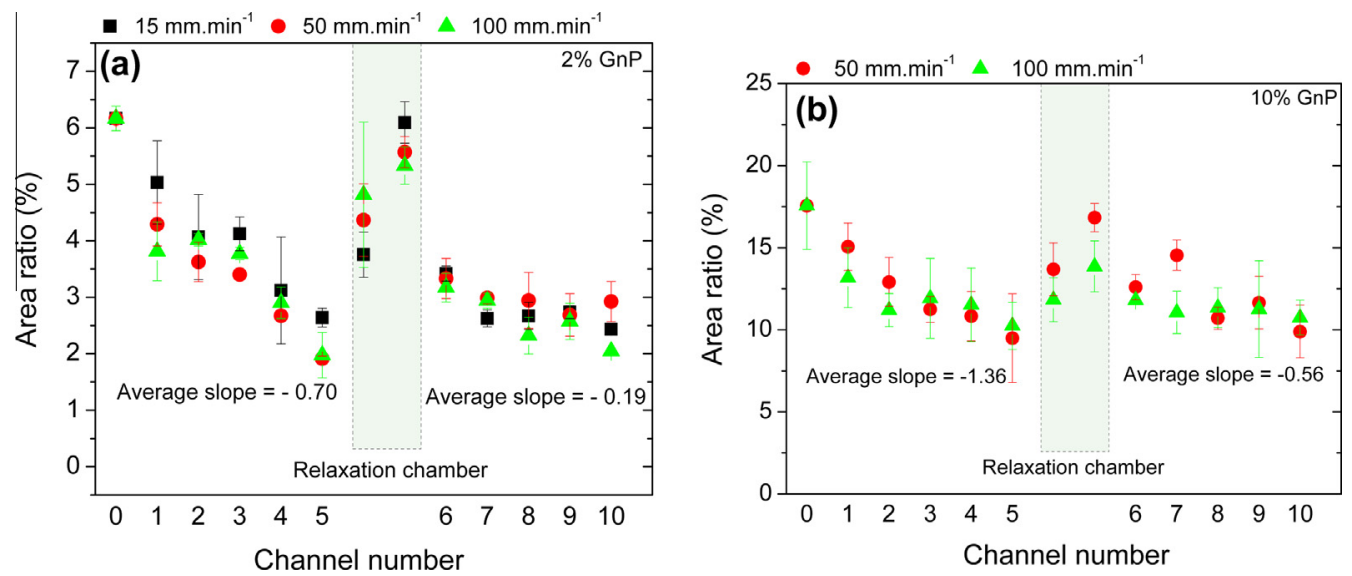

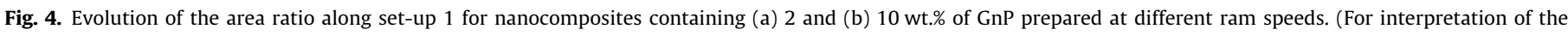
references to colour in this figure legend, the reader is referred to the web version of this article.)

of nanocomposite cross-sections obtained by cryo-fracture, showing the morphology of nanocomposites with $10 \mathrm{wt} . \%$ of $\mathrm{GnP}$ prepared at $50 \mathrm{~mm} \mathrm{~min}^{-1}$. The GnP agglomerates are larger at the reservoir and relaxation chamber and smaller at channel 5 and channel 10. However, the cohesion of the latter seems lower than that of those upstream (the same is valid for channel 10 in set-up 2, to be discussed below). Although further investigation is obviously necessary to clarify this point, this observation could eventually elucidate the underlying differences in dispersion evolution between the two mixing zones. Disregarding the possible contribution of erosion, in the first zone an abrupt rupture of particles probably takes place, whereas in the second mixing zone the smaller particles created upon rupture of an agglomerate become loosely attached to each other, appearing as a large single agglomerate at the magnification of optical microscopy.

The electrical conductivity measured for extruded filaments of PP and nanocomposites is depicted in Fig. 6. The value for neat PP is approximately $10^{-9} \mathrm{~S} \mathrm{~cm}^{-1}$, confirming its insulating nature. After incorporation of 2 and $10 \mathrm{wt} . \%$ of GnP, the electrical conductivity increases approximately 10 times. These values are similar to those reported for a similar PP/GnP system prepared by melt mixing [30], but are still well below the percolation threshold. Not surprisingly, in accordance with the dispersion data, conductivity is barely affected by ram speed.

\subsection{Effect of reprocessing conditions}

The production of nanocomposite parts typically involves two processing steps, the first concerning the preparation of the composite with well dispersed nanoparticles, followed by a second processing step (e.g. extrusion, injection molding) to form the final part. Thus, it seems important to study not only the reagglomeration effects observed during relaxation of the composite melt, but also to analyze the second dispersion step, in particular to evaluate whether agglomerate dispersion is affected by the deformation rate applied during the latter. The geometrical layout of the mixer allows this study by changing the inner diameter of the smaller rings in the second mixing zone. Thus, while the results discussed so far pertain to set-up 1 , where $8: 1$ and 1:8 convergence/divergence series was generated in the two mixing zones (before and after the relaxation chamber), another series of experiments was performed maintaining the geometry of the first mixing zone and imposing a 4:1 and 1:4 convergence/divergence series, by stacking rings with internal diameters of $2 \mathrm{~mm}$ and $8 \mathrm{~mm}$, which was denoted as set-up 2. Fig. 7 displays micrographs illustrating the evolution of the morphology along the mixer for nanocomposites containing 2 and $10 \mathrm{wt} . \%$ of $\mathrm{GnP}$, prepared at $50 \mathrm{~mm} \mathrm{~min}^{-1}$. For each $\mathrm{GnP}$ concentration, the processing conditions are maintained until the relaxation chamber, and no
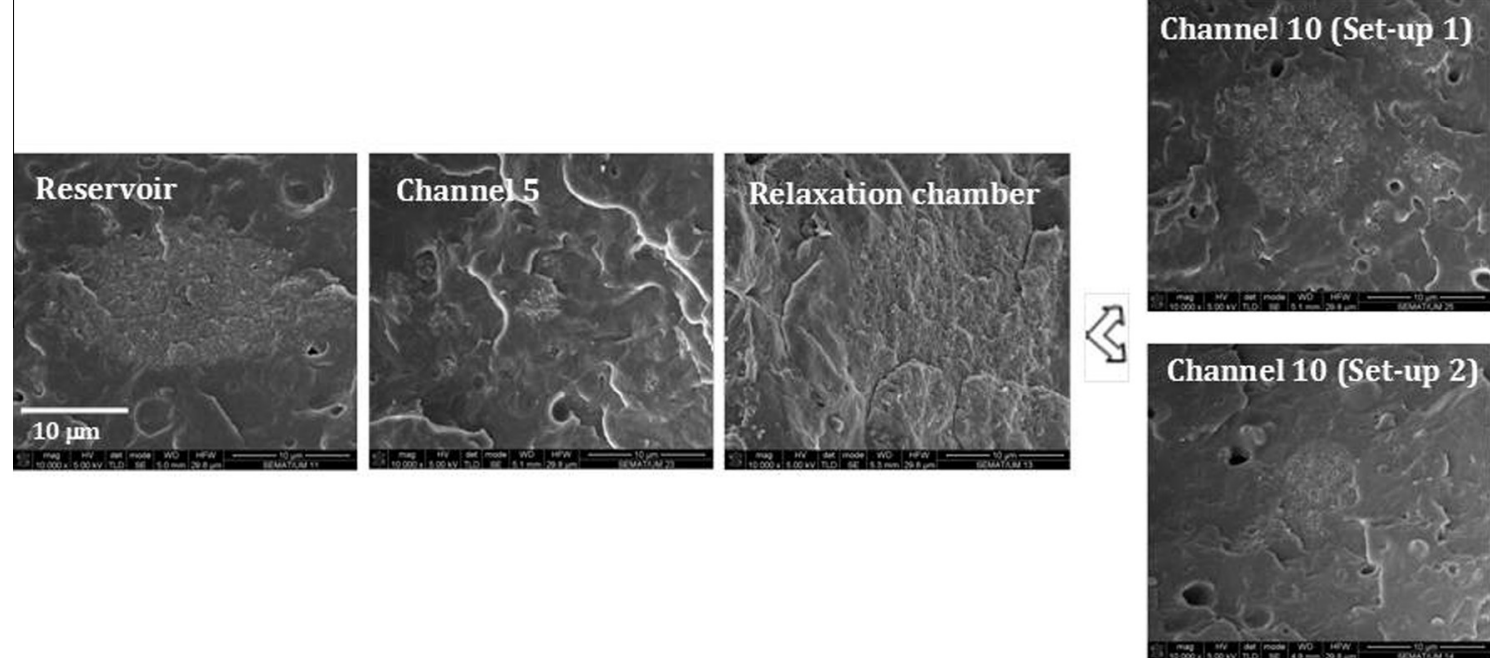

Fig. 5. SEM micrographs of $\mathrm{PP} / 10 \mathrm{wt} . \% \mathrm{GnP}$ nanocomposites prepared at $50 \mathrm{~mm} \mathrm{~min}^{-1}$ using set-ups 1 and 2 . 

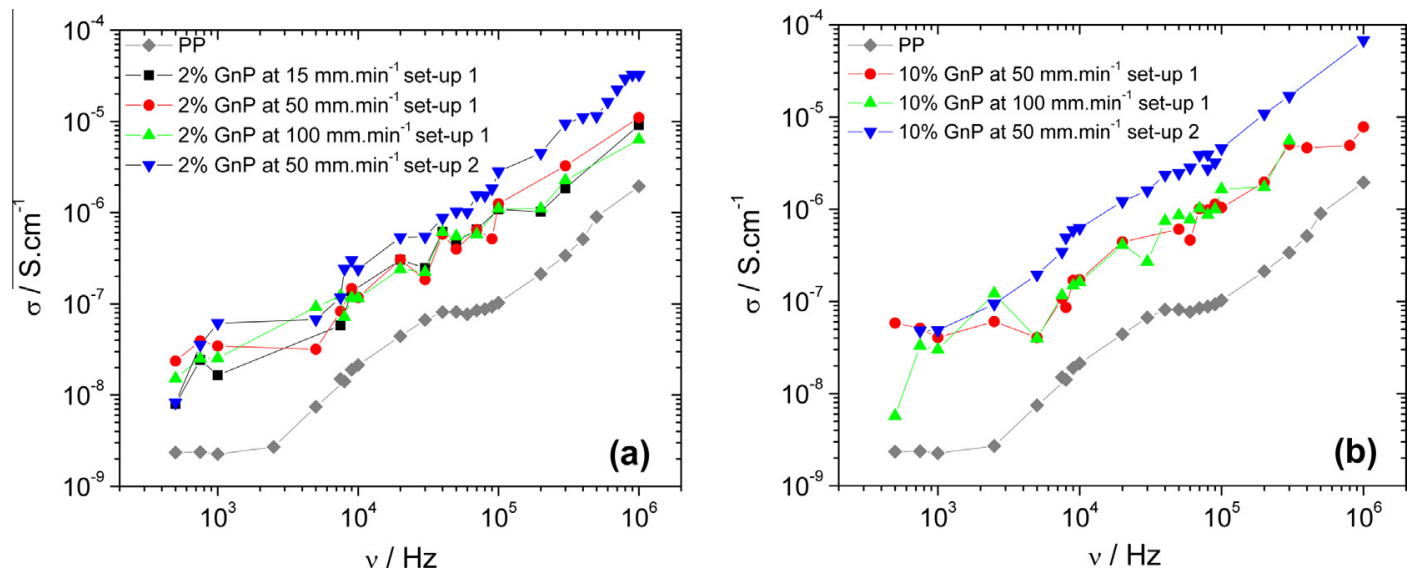

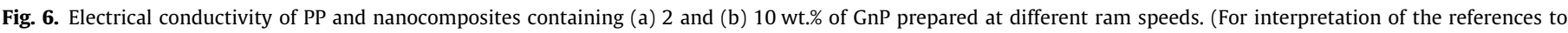
colour in this figure legend, the reader is referred to the web version of this article.)
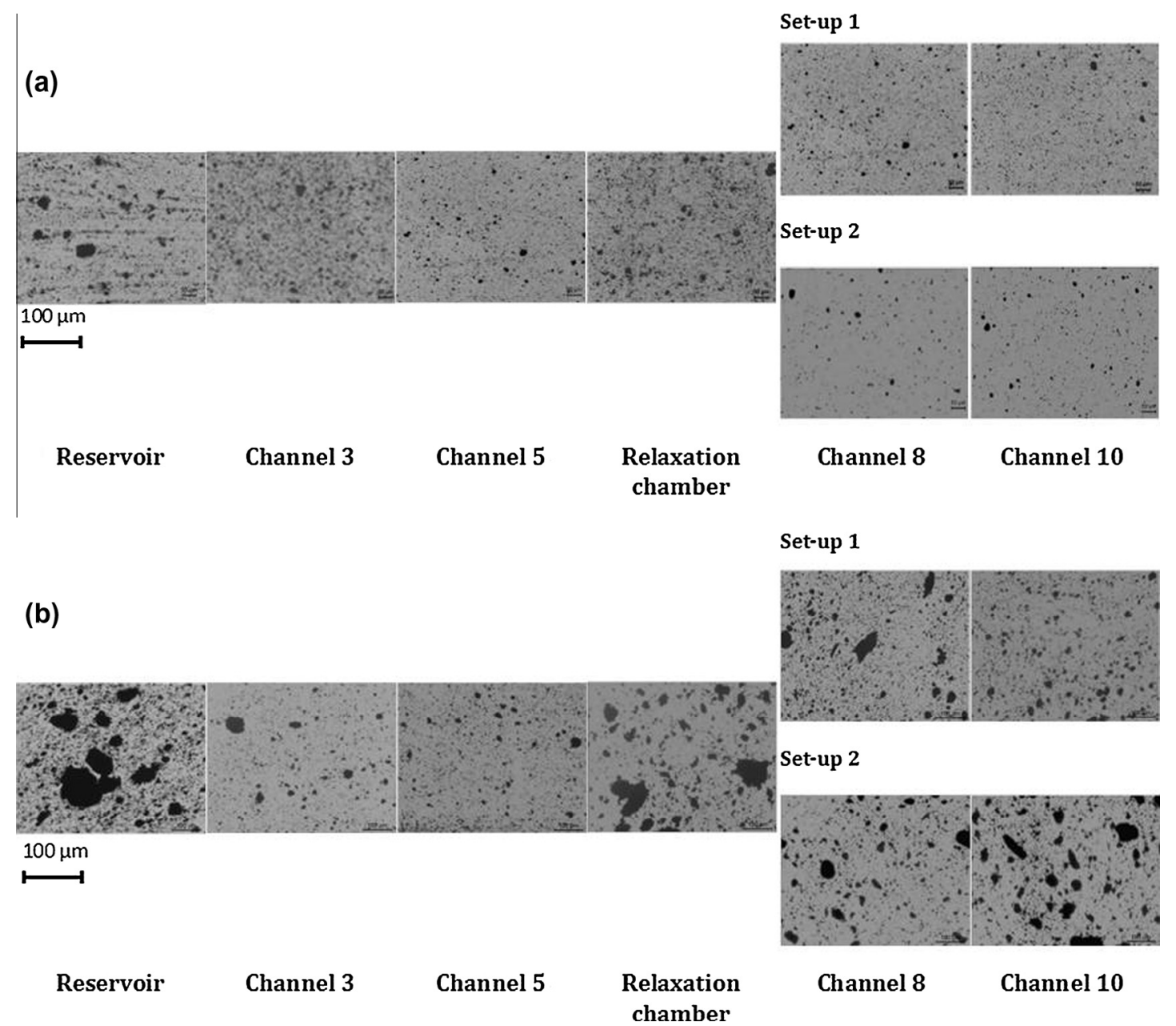

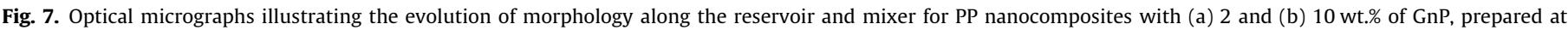
$50 \mathrm{~mm} \mathrm{~min}^{-1}$ using set-ups 1 and 2 .

significant local changes in dispersion were noticed. For $10 \mathrm{wt} . \%$ concentration, the morphology is clearly coarser when using set-up 2 .

Fig. 8 compares the evolution of dispersion along the mixer in terms of the area ratio variation measured for the two nanocomposites with different graphite concentration, processed by the two set-ups. Set-up 2 was observed to yield coarser nanocompos- ites. At lower nanocomposite concentration, the first converging channel after the relaxation chamber induces an important reduction in $A_{r}$ (almost $50 \%$ ), but no further changes are measured downstream. Using set-up 2, the nanocomposite containing 10 wt.\% GnP shows a moderate dispersion effect after the second converging channel of the second mixing zone, but 

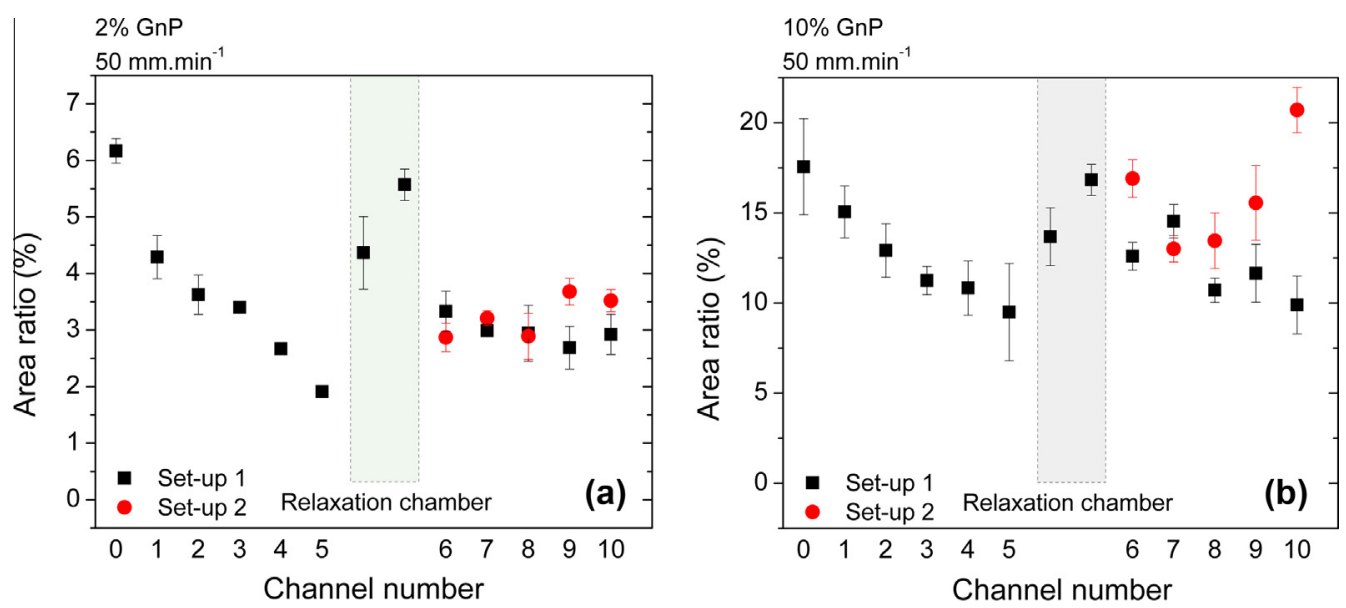

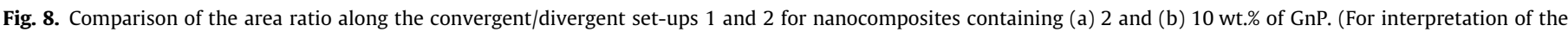
references to colour in this figure legend, the reader is referred to the web version of this article.)

re-agglomeration builds up along the remaining set-up length, and the final nanocomposite is coarser than that obtained at the end of the relaxation chamber. As the convergence ratio along the second mixing zone is changed from $8: 1$ to $4: 1$, the hydrodynamic stress level is reduced significantly, as confirmed by the corresponding pressure drop (see Table 3). The pressure drop in set-up 2 is approximately $40 \%$ lower than that in set-up 1 . Consequently, it appears that the stress build up yields a fragmentation number approaching the critical value for the $2 \mathrm{wt} . \% \mathrm{GnP}$, or remaining below it for the $10 \mathrm{wt}$.\% GnP, maintaining the dispersion level or enabling re-agglomeration, respectively.

The electrical conductivity of PP and nanocomposite is illustrated in Fig. 6. The material produced by set-up 2 has higher conductivity than its equivalent made by set-up 1 . Correlations between nanoparticle dispersion and electrical conductivity remain controversial. While some authors state that a good dispersion of carbon nanotubes within the polymeric matrix is desirable to enhance the composite electrical conductivity [43], others believe that the presence of a network of dispersed particles and agglomerates may form a conductive network structure $[44,45]$. In terms of the mechanical performance, better dispersion is expected to induce higher properties. The results shown in Fig. 8 seem to support the second hypothesis above, i.e., that the presence of aggregated entities of a given magnitude, interconnected by individual GnP sheets, could eventually form an effective conductive path that may be considered as comparable to a cocontinuous morphology containing a (conductive) GnP-rich phase and an (insulating) mostly PP phase.

\section{Conclusions}

The work presented analyzed the effect of melt processing and reprocessing conditions on the dispersion kinetics and reagglomeration of GnP in polypropylene melts. Nanocomposites containing 2 and $10 \mathrm{wt}$ \% of GnP, prepared on a small-scale extensional mixer, showed similar dispersion effects. A gradual decrease of the size and number of $\mathrm{GnP}$ agglomerates occurs along the flow cell, independently of the ram speed. At the relaxation chamber, where the shear rates are negligible, a significant increase of agglomerates size is observed, showing that re-agglomeration took place. Higher dispersion rates are observed for composites with $10 \mathrm{wt} . \%$ of GnP due to the magnitude of the hydrodynamic stresses generated, which result from the higher viscosity. The incorporation of GnP increases the electrical conductivity relative to neat $\mathrm{PP}$ and, in good agreement with the dispersion data, conductivity is almost unaffected by ram speed. The influence of reprocessing conditions on the dispersion of GnP shows that an inferior dispersion level is achieved when reprocessing is performed at lower hydrodynamic stress relative to the processing conditions.

\section{Acknowledgements}

The authors acknowledge the financial support to Project Matepro - Optimizing Materials and Processes (NORTE-07-0124FEDER-000037) by Programa Operacional Regional do Norte (ON.2) and Fundação para a Ciência e Tecnologia, Portugal.

\section{References}

[1] Randviir EP, Brownson DAC, Banks CE. Mater Today 2014;17:426-32.

[2] Singh V, Joung D, Zhai L, Das S, Khondaker SI, Seal S. Prog Mater Sci 2011;56:1178-271.

[3] Shao Y, Wang J, Wu H, Liu J, Aksay IA, Lin Y. Electroanalysis 2010;22:1027-36.

[4] Avouris P. Nano Lett 2010;10:4285-94.

[5] Zhang X, Wang B, Sunarso J, Liu S, Zhi L. Wiley interdisciplinary reviews: energy and environment 2012:1:317-36.

[6] Goenka S, Sant V, Sant S. J Control Release 2014;173:75-88.

[7] Zheng WG, Wong SC, Sue H. J Polym 2002;43:6767.

[8] Dhand V, Rhee KY, Ju Kim H, Ho Jung D. J Nanomater 2013;2013:14.

[9] Dimiev AM, Tour JM. ACS Nano 2014:8:3060-8.

[10] Marcano DC, Kosynkin DV, Berlin JM, Sinitskii A, Sun Z, Slesarev A, et al. ACS Nano 2010;4:4806-14.

[11] Chen J, Yao B, Li C, Shi G. Carbon 2013;64:225-9.

[12] Hummers WS, Offeman RE. J Am Chem Soc 1958;80. 1339-1339.

[13] Pei S, Cheng H-M. Carbon 2012;50:3210-28.

[14] Park S, An J, Potts JR, Velamakanni A, Murali S, Ruoff RS. Carbon 2011:49:3019-23.

[15] Moon IK, Lee J, Ruoff RS, Lee H. Nat Commun 2010;1:73.

[16] Ponomarenko LA, Schedin F, Katsnelson MI, Yang R, Hill EW, Novoselov KS et al. Science 2008;320:356-8.

[17] Dong Y, Lin J, Chen Y, Fu F, Chi Y, Chen G. Nanoscale 2014;6:7410-5.

[18] Kosynkin DV, Higginbotham AL, Sinitskii A, Lomeda JR, Dimiev A, Price BK, et al. Nature 2009;458:872-6.

[19] Bai J, Zhong X, Jiang S, Huang Y, Duan X. Nat Nano 2010;5:190-4.

[20] Zhang Y, Zhang L, Zhou C. Acc Chem Res 2013;46:2329-39.

[21] Kim J, Bayram C, Park H, Cheng C-W, Dimitrakopoulos C, Ott JA, et al. Nat Commun 2014:5.

[22] Chung DDL. J Mater Sci 1987;22:4190-8.

[23] Bianco A, Cheng H-M, Enoki T, Gogotsi Y, Hurt RH, Koratkar N, et al. Carbon 2013;65:1-6.

[24] Wakabayashi K, Pierre C, Dikin DA, Ruoff RS, Ramanathan T, Brinson LC, et al Macromolecules 2008;41:1905-8.

[25] Song P, Cao Z, Cai Y, Zhao L, Fang Z, Fu S. Polymer 2011;52:4001-10.

[26] Kalaitzidou K, Fukushima H, Drzal LT. Carbon 2007;45:1446-52.

[27] Kalaitzidou K, Fukushima H, Askeland P, Drzal L. J Mater Sci 2008;43:2895-907.

[28] Kalaitzidou K, Fukushima H, Drzal LT. Compos A. Appl Sci Manuf 2007:38:1675-82.

[29] Duguay A, Nader J, Kiziltas A, Gardner D, Dagher H. Appl Nanosci 2014;4:279-91. 
30] Kalaitzidou K, Fukushima H, Drzal LT. Compos Sci Technol 2007;67:2045-51.

[31] Milani MA, González D, Quijada R, Basso NRS, Cerrada ML, Azambuja DS, et al. Compos Sci Technol 2013;84:1-7.

[32] Nguyen XQ, Utracki LA. US Patent 5, 451, 106, 19 September 1995 to Nacional Research Council Canada.

[33] Tokihisa M, Yakemoto K, Sakai T, Utracki LA, Sepehr M, Li J, et al. Polym Eng Sci 2006; $46: 1040-50$

[34] Novais RM, Covas JA, Paiva MC. Compos A. Appl Sci Manuf 2012;43:833-41.

[35] Jamali S, Paiva MC, Covas JA. Polym Testing 2013;32:701-7.

[36] Kasaliwal GR, Pegel S, Göldel A, Pötschke P, Heinrich G. Polymer 2010;51:2708-20

[37] McLachlan DS, Chiteme C, Park C, Wise KE, Lowther SE, Lillehei PT, et al. ] Polym Sci, Part B: Polym Phys 2005;43:3273-87.
[38] Manas-Zloczower I. Mixing and compounding of polymers: theory and practice. Hanser; 2009.

[39] Grace HP. Chem Eng Commun 1982;14:225-77.

[40] Scurati A, Feke DL, Manas-Zloczower I. Chem Eng Sci 2005;60:6564-73.

[41] Litchfield DW, Baird DG. Rheol Rev 2006:1-60.

[42] Domingues N, Gaspar-Cunha A, Covas JA, Camesasca M, Kaufman M, ManasZloczower I. Int Polym Proc 2010;25:188-98.

[43] Ma P-C, Siddiqui NA, Marom G, Kim J-K. Compos A. Appl Sci Manuf 2010;41:1345-67.

[44] Pegel S, Pötschke P, Petzold G, Alig I, Dudkin SM, Lellinger D. Polymer 2008;49:974-84.

[45] Vasileiou AA, Kontopoulou M, Docoslis A. ACS Appl Mater Interfaces 2014;6:1916-25. 